\title{
A Consensus on the Diagnosis and Treatment of Acromegaly Comorbidities: An Update
}

Andrea Giustina $^{1}$, Ariel Barkan ${ }^{2}$, Albert Beckers $^{3}$, Nienke Biermasz ${ }^{4}$, Beverly M.K. Biller ${ }^{5}$, Cesar Boguszewski ${ }^{6}$, Marek Bolanowski ${ }^{7}$, Vivien Bonert ${ }^{8}$, Marcello D. Bronstein ${ }^{9}$, Felipe F. Casanueva $^{10}$, David Clemmons ${ }^{11}$, Annamaria Colao ${ }^{12}$, Diego Ferone ${ }^{13}$, Maria Fleseriu ${ }^{14}$, Stefano Frara $^{1}$, Monica R. Gadelha ${ }^{15}$, Ezio Ghigo ${ }^{16}$, Mark Gurnell ${ }^{17}$, Anthony P. Heaney ${ }^{18}$, Ken Ho ${ }^{19}$, Adriana Ioachimescu ${ }^{20}$, Laurence Katznelson ${ }^{21}$, Fahrettin Kelestimur ${ }^{22}$, John Kopchick ${ }^{23}$, Michal $\mathrm{Krsek}^{24}$, Steven Lamberts ${ }^{25}$, Marco Losa ${ }^{26}$, Anton Luger ${ }^{27}$, Pietro Maffei ${ }^{28}$, Monica Marazuela ${ }^{29}$, Gherardo Mazziotti $^{30}$, Moises Mercado ${ }^{31}$, Pietro Mortini ${ }^{26}$, Sebastian Neggers ${ }^{32}$, Alberto M. Pereira $^{4}$, Stephan Petersenn ${ }^{33}$, Manel Puig-Domingo ${ }^{34}$, Roberto Salvatori $^{35}$, Ilan Shimon ${ }^{36}$, Christian Strasburger ${ }^{37}$, Stylianos Tsagarakis ${ }^{38}$, A.J. van der Lely ${ }^{32}$, John Wass ${ }^{39}$, Maria Chiara Zatelli $^{40}$, Shlomo Melmed ${ }^{8}$

${ }^{1}$ Division of Endocrinology and Metabolism, San Raffaele University Hospital, Milan, Italy

${ }^{2}$ Division of Endocrinology, University of Michigan Health System, Ann Arbor, Michigan, USA

${ }^{3}$ Department of Endocrinology, University of Liège, Liège, Belgium

${ }^{4}$ Division of Endocrinology and Center for Endocrine Tumors, Department of Medicine, Leiden University Medical Center, Leiden, The Netherlands

${ }^{5}$ Neuroendocrine Unit, Massachusetts General Hospital, Harvard Medical School, Boston, Massachusetts, USA

${ }^{6}$ SEMPR, Endocrine Division, Department of Internal Medicine, Federal University of Parana, Curitiba, Brazil 
${ }^{7}$ Department of Endocrinology, Diabetes and Isotope Therapy, Wroclaw Medical University, Wroclaw, Poland

${ }^{8}$ Department of Medicine, Cedars-Sinai Medical Center, Los Angeles, California, USA

${ }^{9}$ Division of Endocrinology and Metabolism, Hospital das Clinicas, University of Sao Paulo, Sao

Paulo, Brazil

${ }^{10}$ Division of Endocrinology, Santiago de Compostela University and Ciber OBN, Santiago de Compostela, Spain

${ }^{11}$ Department of Medicine, University of North Carolina, Chapel Hill, North Carolina, USA

${ }^{12}$ Division of Endocrinologia, Universita' Federico II di Napoli, Naples, Italy

${ }^{13}$ Endocrinology Unit, Department of Internal Medicine, University of Genoa, Genoa, Italy

${ }^{14}$ Departments of Medicine and Neurological Surgery, Pituitary Center, Oregon Health \& Science University, Portland, Oregon, USA

${ }^{15}$ Neuroendocrinology Research Center/Endocrinology Section, Medical School and Hospital Universitário Clementino Fraga Filho, Universidade Federal do Rio de Janeiro, Rio de Janeiro, Brazil

${ }^{16}$ Division of Endocrinology and Metabolism, Department of Internal Medicine, University of Turin, Turin, Italy

${ }^{17}$ University of Cambridge \& Addenbrooke's Hospital, Metabolic Research Laboratories, Wellcome Trust-MRC Institute of Metabolic Science, Cambridge, United Kingdom

${ }^{18}$ Division of Endocrinology, Diabetes and Hypertension, Department of Medicine, David Geffen School of Medicine, University of California, Los Angeles, California, USA

${ }^{19}$ The Garvan Institute of Medical Research and St. Vincent's Hospital, Sydney, Australia 
${ }^{20}$ Department of Medicine, Division of Endocrinology, Metabolism and Lipids, and Department of Neurosurgery, Emory University School of Medicine, Atlanta, Georgia, USA

${ }^{21}$ Departments of Medicine and Neurosurgery, Stanford University School of Medicine,

Stanford, California, USA

${ }^{22}$ Yeditepe University, Faculty of Medicine, Istanbul, Turkey

${ }^{23}$ Edison Biotechnology Institute and Department of Biomedical Sciences, Ohio University, Athens, Ohio, USA

${ }^{24} 2$ nd Department of Medicine, 3rd Faculty of Medicine of the Charles University and University Hospital Kralovske Vinohrady, Prague, Czech Republic

${ }^{25}$ Erasmus Medical Center, Rotterdam, The Netherlands

${ }^{26}$ Department of Neurosurgery, San Raffaele University Health Institute Milan, Milan, Italy

${ }^{27}$ Division of Endocrinology and Metabolism, Medical University of Vienna, Vienna, Austria

${ }^{28}$ Department of Medicine, Padua University Hospital, Padua, Italy

${ }^{29}$ Department of Medicine, CIBERER, Universidad Autónoma de Madrid, Madrid, Spain

${ }^{30}$ Endocrinology Unit, Humanitas University and Humanitas Clinical and Research Center,

Rozzano, Milan, Italy

${ }^{31}$ Division of Medicine, National Autonomous University of Mexico, Experimental

Endocrinology Unit, Centro Médico Nacional, Siglo XXI, IMSS, Mexico City, Mexico

${ }^{32}$ Pituitary Center Rotterdam, Endocrinology Section, Department of Internal Medicine, Erasmus

University Medical Center, Rotterdam, The Netherlands

${ }^{33}$ ENDOC Center for Endocrine Tumors, Hamburg, Germany

${ }^{34}$ Endocrinology Service, CIBER and CIBERES Germans Trias i Pujol Research Institute and Hospital, Autonomous University of Barcelona, Badalona, Spain 
${ }^{35}$ Division of Endocrinology, Diabetes, and Metabolism and Pituitary Center, Johns Hopkins School of Medicine, Baltimore, USA

${ }^{36}$ Endocrine Institute, Rabin Medical Center, Beilinson Hospital, Petah-Tikva, Israel

${ }^{37}$ Department of Medicine for Endocrinology, Diabetes and Nutritional Medicine, Charité Universitätsmedizin, Berlin, Germany

${ }^{38}$ Department of Endocrinology, Diabetes and Metabolism, Evangelismos Hospital, Athens, Greece

${ }^{39}$ Department of Endocrinology, Oxford Centre for Diabetes, Endocrinology and Metabolism, Churchill Hospital, Oxford, United Kingdom

${ }^{40}$ Section of Endocrinology \& Internal Medicine, Department of Medical Sciences, University of Ferrara, Ferrara, Italy

Disclosure Summary: BMKB, MB, MDB, VB, DC, MF, AG, AI, AL, MM, SN, SP, CS, IS, RS, and AVDL have received consulting fees from Pfizer. BMKB, DF, MF, AG, MRG, APH, AL, ML, GM, MM, SM, SP, CS, IS, and MCZ have received consulting fees from Novartis. DC, DF, MF, AG, AL, ML, GM, SN, SP, and CS have received consulting fees from Ipsen. DC, MF, AG, LK, SM, and CS have received consulting fees from Chiasma. DC and SN have received consulting fees from Crinetics. MF and SM have received consulting fees from Ionis and Ono. MG has received consulting fees from AstraZeneca. DF has received consulting fees from Bristol-Myers Squibb. ML has received consulting fees from Eli Lilly. SM has received consulting fees from Midatech. APH and RS have received consulting fees from Novo Nordisk. MCZ has received consulting fees from Sanofi. APH has received consulting fees from Strongbridge. AB, BMKB, MB, MDB, DF, MF, MRG, AI, LK, and RS have received fees for 
contracted research from Novartis. MB, MDB, FFC, DF, MF, MRG, and RS have received fees for contracted research from Ipsen. FFC, MF, AI, PM, SM, and RS have received fees for contracted research from Pfizer. MB, MF, AI, and MPD have received fees for contracted research from Chiasma. $\mathrm{MB}, \mathrm{KH}$, and $\mathrm{RS}$ have received fees for contracted research from Novo Nordisk. MB and RS have received fees for contracted research from Strongbridge. MB has received fees for contracted research from HRA Pharma. MF has received fees for contracted research from Ionis and Ono. RS has received fees for contracted research from Opko Biologics. $\mathrm{KH}$ has received fees for contracted research from Versartis. $\mathrm{CB}, \mathrm{MB}, \mathrm{MDB}, \mathrm{MG}, \mathrm{KH}, \mathrm{AL}$, MM, and MPD have served as a member of the speakers bureau for Ipsen. CB, MB, MDB, MG, $\mathrm{KH}, \mathrm{AL}, \mathrm{MM}$, and MPD have served as members of the speakers bureau for Novartis. $\mathrm{CB}, \mathrm{MB}$, FFC, MG, and AL have served as members of the speakers bureau for Pfizer. MK has received lecture fees from Merck, Eli Lilly, and Shire. MRG has received lecture fees from Novartis.

AVDL has an ownership interest in Millendo Therapeutics. AB, NB, AC, SF, EG, FK, JK, SL, PM, AP, ST, and JW have nothing to declare.

Keywords: acromegaly, consensus, comorbidities, diagnosis, treatment

Corresponding author and address to whom reprint requests should be addressed: Shlomo Melmed, MD, Academic Affairs, Cedars-Sinai Medical Center, 8700 Beverly Blvd., Room 2015, Los Angeles, CA, 90048, USA. Tel: (310) 423-4691. Email: melmed@ csmc.edu. 


\begin{abstract}
Objective: The aim of the Acromegaly Consensus Group was to revise and update the consensus on diagnosis and treatment of acromegaly comorbidities last published in 2013.

Participants: The Consensus Group, convened by 11 Steering Committee members, consisted of 45 experts in the medical and surgical management of acromegaly. The authors received no corporate funding or remuneration.
\end{abstract}

Evidence: This evidence-based Consensus was developed using the Grading of Recommendations, Assessment, Development, and Evaluation (GRADE) system to describe both the strength of recommendations and the quality of evidence following critical discussion of the current literature on the diagnosis and treatment of acromegaly comorbidities.

Consensus Process: Acromegaly Consensus Group participants conducted comprehensive literature searches for English-language papers on selected topics, reviewed brief presentations on each topic, and discussed current practice and recommendations in breakout groups. Consensus recommendations were developed based on all presentations and discussions. Members of the Scientific Committee graded the quality of the supporting evidence and the consensus recommendations using the GRADE system.

Conclusions: Evidence-based approach consensus recommendations address important clinical issues regarding multidisciplinary management of acromegaly-related cardiovascular, endocrine, metabolic, and oncologic comorbidities, sleep apnea, and bone and joint disorders and their sequelae, as well as their effects on quality of life and mortality. 


\section{Precis}

The Acromegaly Consensus Group presents evidence-based recommendations for optimizing diagnosis and treatment of acromegaly comorbidities.

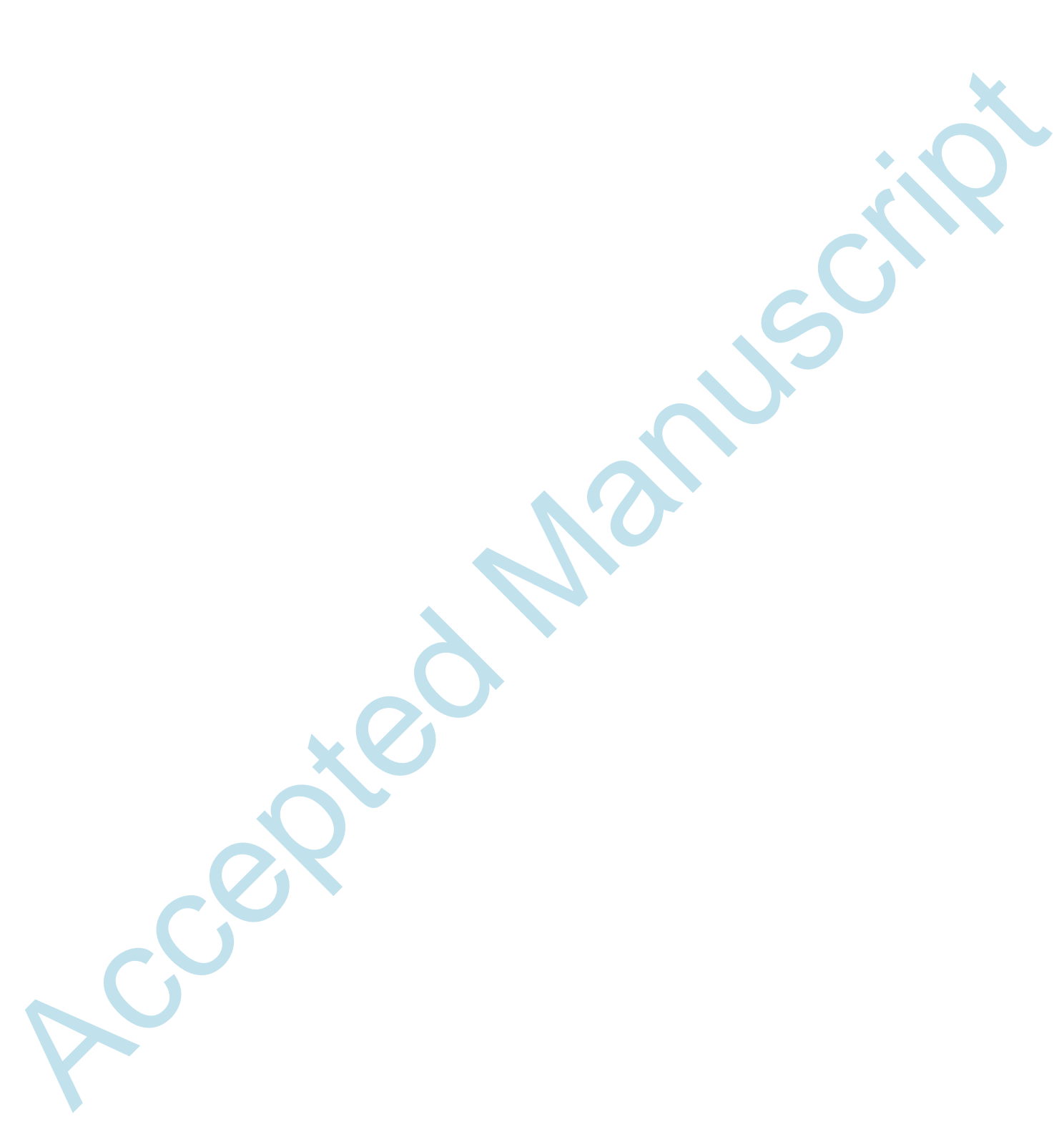




\section{Introduction}

Excess levels of circulating growth hormone (GH) and insulin-like growth factor (IGF)-I in acromegaly have deleterious effects on a wide range of tissues and physiologic processes $(1,2)$. Patients commonly experience abnormal growth of bone and soft tissue $(3,4)$ and have dysregulated glucose metabolism $(5,6)$ with increased risk for cardiovascular disease $(7)$, all of which may impact mortality risk (8). Treatment of patients with acromegaly is aimed at controlling excess GH and/or IGF-I levels, but signs and symptoms of the disease often persist despite achievement of biochemical control $(1,9,10)$. The diagnosis and optimal management of acromegaly comorbidities is critical to ensuring the best long-term outcome for this chronic illness.

The Acromegaly Consensus Group published the first set of recommendations on diagnosis and treatment of disease complications in 2003 (11), and updated them in 2013 (12). In concert with development of new disease management protocols (9), and the conceptualization of the Pituitary Tumor Center of Excellence (13), investigators have increasingly been focusing on defining and optimizing management strategies for acromegaly comorbidities and disease-related sequelae. In June 2018, 45 experts in acromegaly management reviewed the literature and critically assessed new research findings and changes in clinical practice standards and clinical opinion since the 2013 consensus publication. Discussions focused on: cardiovascular, endocrine, metabolic, and oncologic comorbidities, sleep apnea, and bone and joint disorders, as well as the impact of these disease sequelae on quality of life (QoL) and mortality. Updated consensus recommendations on diagnosis and treatment of acromegaly comorbidities were graded using the Grading of Recommendations Assessment, Development and Evaluation 
system (GRADE; Table 1) $(14,15)$ and key consensus recommendations are presented in Table 2.

\section{Materials and Methods}

The process for development of consensus recommendations by Acromegaly Consensus Group participants before and during the meeting has been described (9). Briefly, participants were assigned specific topics related to acromegaly complications and conducted comprehensive literature searches for English-language papers published between March 2011 and May 2018. Search terms included "acromegaly" and "comorbidities" as well as terms associated with each respective topic covered. After brief presentations to the entire group on each topic, breakout groups discussed current practice and recommendations, and a summary of the findings reported back to the entire group. Consensus recommendations were developed based on all presentations and discussions and all participants voted on each recommendation. After the meeting, members of the Scientific Committee graded both the quality of the supporting evidence and the consensus recommendations using the GRADE system (Table 1). Evidence was graded by strength as very low quality (VLQ), low quality (LQ), moderate quality (MQ), or high quality (HQ). Recommendations were classified as discretionary (DR) or strong (SR).

\section{Cardiovascular Disease}

Although cardiovascular morbidity has improved significantly, cardiovascular disease is still an important cause of mortality among patients with acromegaly, despite the recent shift to cancer as the leading cause of mortality (16-18) and rates among those with well-controlled acromegaly now closely approximating that of the normal aging population (MQ). It remains unclear how 
much of this shift is due to improved treatment of acromegaly and its comorbidities versus overall improved cardiac care and more stringent cardiovascular risk management; further studies are needed to distinguish between these factors.

Hypertension is a major contributor to cardiovascular mortality in acromegaly (HQ) (8), but recent reports have indicated the positive impact of effective medical control. Prevalence is estimated at approximately $30 \%$ and may be as high as $60 \%$ in some series $(19,20)$, with markedly higher rates seen in patients with biochemically uncontrolled acromegaly (MQ) $(7,21)$. Excess GH leads to insulin resistance, endothelial dysfunction, and increased sodium and water retention resulting in increased plasma volume and leading to hypertension (22), but these effects may not be fully reversible, and hypertension may persist despite biochemical control of acromegaly (MQ) (23). Management of hypertension in acromegaly should be consistent with guidelines for the general population (SR).

Arrhythmia is relatively uncommon (24), and, when present, is likely related to structural heart disease, particularly cardiomyopathy (LQ) (25). However, patients may exhibit a prolonged QT interval (MQ) (26). Treatment selection for acromegaly should therefore consider potential effects on QT interval (SR). Study data suggest a possible risk of QT interval prolongation with pasireotide (27). Although the clinical relevance of this effect is unclear, monitoring prior to and during treatment is advisable (28). Retrospective data on octreotide/lanreotide in acromegaly patients do not suggest similar effects $(27,29)$. Contributing risk from concomitant therapies that prolong QT interval should also be evaluated (DR).

As subclinical cardiomyopathy may be present (30), baseline echocardiogram is indicated (SR). Although prevalence of left ventricular hypertrophy (LVH) may be lower than earlier reports suggested, due to overdiagnosis, earlier diagnosis of acromegaly, and/or overestimation 
of damage by echocardiography (LQ) (31), assessment of changes in cardiac structure is important for long-term management. Magnetic resonance imaging is not required to determine the most appropriate treatment (DR).

Heart failure occurs uncommonly in acromegaly, and is likely influenced by risk factors such as disease duration and severity, the presence of hypertension and diabetes mellitus, and family history (MQ) (32). The significance of cardiac valve disease with regurgitation specific to acromegaly is difficult to assess as tricuspid insufficiency is relatively common in the general population and other factors, such as hypertension, likely influence its risk (LQ).

Prevalence of ischemic heart disease is not increased due to acromegaly per se $(33,34)$. Risk is likely more related to common risk factors such as hypertension, hyperlipidemia, disturbed glucose homeostasis, and smoking (LQ).

Biochemical control of acromegaly with SRLs and pegvisomant reduces LVH progression and improves other markers of structural cardiac dysfunction, including left ventricular ejection fraction (MQ) $(35,36)$. By contrast, the incidence of valvular abnormalities and the risk for further progression of valvulopathy remain unchanged (LQ) (37). Data are reassuring regarding the risk for cardiac valve disease in patients with acromegaly treated with cabergoline (38) but additional studies are needed (VLQ).

\section{Endocrine and Metabolic Disorders}

\section{Diabetes mellitus}

Impaired glucose tolerance and diabetes mellitus (DM) are the most frequent metabolic comorbidities and are present in $30 \%$ to $50 \%$ of patients at diagnosis (HQ) $(39,40)$. This rate is 
expected to rise further as the prevalence of DM continues to increase in the general population (VLQ).

Acromegaly patients develop insulin resistance due to GH excess, and in those with longstanding disease, insulin insufficiency with impaired glucose tolerance may also occur (MQ) (41). Accordingly, if antidiabetic therapy is necessary, DM should be managed as for the general population and metformin considered as first-line therapy (SR). Tighter $\mathrm{HbAlc}$ control is recommended for younger patients (DR). Glucagon-like peptide (GLP)-1 agonists and dipeptidyl peptidase (DPP-4) inhibitors are largely untested and should be considered as second-line treatment on an individualized basis (DR). Sodium-glucose cotransporter (SGLT)-2 inhibitors may be a less favorable option due to increased risk for ketoacidosis in patients with acromegaly (DR) (42).

Importantly, the presence of DM influences the choice of acromegaly medical therapy (MQ). Octreotide and lanreotide generally have a neutral effect on glucose control (MQ) (43), although monitoring of glycemia is advisable (SR). Pasireotide is not recommended in patients with uncontrolled DM due to the high risk for developing hyperglycemia (SR) $(9,44,45)$. The decision to continue pasireotide in a patient who develops hyperglycemia should be individualized. If the benefits of continuing pasireotide outweigh hyperglycemic risk, data from healthy subjects suggest that treatment with concomitant GLP-1 agonists or DPP-4 inhibitors may be useful in minimizing the hyperglycemic effect (DR) (46), but real-world applicability to acromegaly patients on long-term pasireotide remains unknown. Pegvisomant treatment improves glucose metabolism in acromegaly patients $(47,48)$ and should be considered in patients with partial or no response to first-line medical therapy for whom glycemic control is challenging (SR) (9). 
Considering the negative effects of disturbed glucose homeostasis on patient outcomes, including mortality risk (MQ) $(8,49)$, all acromegaly patients should be screened for dysglycemia at diagnosis and during follow-up by fasting blood glucose or oral glucose tolerance and $\mathrm{HbA} 1 \mathrm{c}$ assessment (SR). Consequent therapy for hyperglycemia is mandatory for optimizing outcome.

\section{Hypopituitarism}

Hypogonadism is detected in approximately $50 \%$ of patients and results from tumor mass effect, and/or concomitant hyperprolactinemia (MQ) (50,51). Hypogonadism may compromise sexual function, fertility, body composition, well-being, and bone health; proper assessment and adequate replacement of hormonal deficits is recommended (SR) (10). As acromegaly can lead to decreased sex hormone binding globulin (SHBG) levels (LQ) (52), free testosterone should be measured or free testosterone indices should be calculated to assess gonadal function in males with active acromegaly to avoid overdiagnosis of hypogonadism (DR).

Gonadal steroids significantly modulate the GH/IGF system. Testosterone enhances action of $\mathrm{GH}$; estrogens, when taken orally, reduces hepatic IGF-I production, thereby indirectly attenuating GH action (LQ) (53). Therefore, the choice and route of gonadal steroid replacement can significantly affect underlying acromegaly disease activity. Selective estrogen receptor modulators (SERMs) are synthetic estrogen-like compounds with tissue-specific agonist and antagonist actions. As such, they may be used to modulate disease activity in acromegaly, improving gonadal activity via central antiestrogen action while also reducing hepatic IGF-I production via estrogen agonist action (VLQ) (54).

Insufficient replacement of other pituitary hormone deficiencies, such as in central hypothyroidism, or over-replacement of glucocorticoids in adrenal insufficiency may result in 
dyslipidemia and increased cardiovascular risk (LQ) $(55,56)$. High doses of glucocorticoid replacement have also been associated with increased mortality risk (VLQ) (57). However, as the GH/IGF-I axis affects cortisol metabolism (58), careful assessment of hormone replacement strategies is recommended (SR) (59).

Conventional radiation therapy increases risk for hypopituitarism and contributes to higher mortality rates (MQ) (57). These patients require careful long-term monitoring for the development of hormonal deficits. It is as yet unknown whether modern radiosurgical approaches are associated with a reduced impact on mortality compared with conventional radiotherapy (VLQ).

\section{Obstructive sleep apnea}

Obstructive sleep apnea (OSA) is detected in up to $80 \%$ of newly diagnosed acromegaly patients (HQ) (40,60-62), and results mainly from pharyngeal soft tissue swelling characteristic of acromegaly (MQ) $(63,64)$. OSA has well-described adverse effects on the cardiovascular system, and is an independent risk factor for ischemic heart disease, arrhythmia, cardiomyopathy, and other cardiovascular disorders (MQ).

Every patient should undergo careful assessment for OSA at diagnosis of acromegaly; this includes a thorough history, questioning of spouse/partner, and potentially use of a sleep questionnaire, such as the Epworth sleepiness scale (SR) (65). If OSA is suspected on screening, polysomnography could be considered before initial acromegaly surgery. In patients with severe pharyngeal swelling, polysomnography may be performed and pre-operative medical treatment with an SRL considered (DR). 
Effective treatment of acromegaly, with reduction of GH/IGF-I, and concomitant reduction in soft tissue swelling, may significantly improve OSA. Nevertheless, because OSA may persist or worsen despite appropriate acromegaly therapy (MQ) $(61,66,67)$, post-treatment evaluation is essential and regular monitoring recommended. Continuous positive airway pressure (CPAP) with a specially fitted mask may be necessary for patients with atypical facial morphometry due to acromegaly (SR). Management of disordered breathing should be undertaken jointly with a sleep physician.

\section{Dyslipidemia}

Prevalence of dyslipidemia in acromegaly is generally similar to that of the general population. Lipoprotein(a) may be elevated while HDL cholesterol may be lower (VLQ) $(68,69)$, but the clinical significance of these findings is unclear. Diagnosis, treatment, and management of dyslipidemia should follow guidelines for the general population (SR), with treatment goals and regimens accounting for presence of other metabolic comorbidities of acromegaly, such as diabetes mellitus and hypertension (DR).

\section{Musculoskeletal Disorders}

\section{Arthropathy}

Acromegaly is associated with specific GH- and IGF-I induced joint changes that increase the risk for arthropathy (HQ) $(3,70,71)$. Cartilage hypertrophy and osteophyte formation contribute to joint space narrowing that may initially be reversible (VLQ) (3). Over time, however, joint degeneration may progress despite biochemical control, with radiological progression seen in the 
majority of patients even after long-term disease control (MQ) (72). Early diagnosis and treatment of acromegaly may therefore improve reversibility of arthropathy (SR).

Arthropathy pain is one of the most prominent symptoms negatively affecting QoL in patients with acromegaly, and can result in significant deterioration of function over time (MQ) (73). Treatment of arthropathy should follow guidelines as for the general population (SR). However, clinical and radiological findings of acromegaly-associated arthropathy differ from those of primary osteoarthritis (74), and should be considered when selecting an intervention $\operatorname{approach}(\mathrm{DR})$.

\section{Carpal tunnel syndrome}

Carpal tunnel syndrome in acromegaly is caused by median nerve enlargement and resultant delayed conduction velocity that correlates with disease duration and IGF-I level (MQ) (75,76). Most patients show symptomatic improvement with acromegaly control, although increased nerve diameter may not be reversible despite treatment (LQ) $(76,77)$. Depending on the severity of symptoms, nerve conduction and imaging studies and decompression surgery may be warranted (DR).

\section{Vertebral fractures}

Fractures of the vertebrae detected with vertebral morphometry, particularly of the thoracic spine, are highly prevalent in acromegaly patients with active disease, reported to affect up to $60 \%$ of patients (HQ) $(78,79)$. Estimates from available data suggest a 3 -fold to 8 -fold higher prevalence than in the general population, and a slight predominance in males vs females (LQ) (80). Excess GH and IGF-I, which play key roles in bone metabolism, lead to increased bone 
turnover and deterioration of cortical and trabecular bone structure (MQ) (80-83). Accordingly, fracture risk is highest in patients with long-standing active acromegaly. Biochemical control corrects bone turnover defects and protects against fracture risk (MQ) (81,84-86). Lumbar spine trabecular bone score, related to bone microarchitecture, provides information on bone strength independent of BMD (80). However, some patients with biochemically controlled acromegaly may still have a higher risk of vertebral fracture as a result of permanent or irreversible alterations in bone structure (MQ) $(78,82,87)$. Notably, although prevalence of vertebral fracture is higher in eugonadal men with acromegaly than in healthy controls (78), hypogonadism is a significant independent risk factor for increased incidence and adverse outcome of fracture (MQ) (87) and androgen replacement therapy should be considered in hypogonadal men and estrogen substitution considered in postmenopausal women (SR).

Because the presence of a vertebral fracture is a strong predictor of subsequent fractures, and because optimization of biochemical control as well as correction of other risk factors (eg, hypogonadism) may reduce these events (80), imaging studies to assess bone morphometry are suggested in all patients at diagnosis, regardless of disease status (SR), with follow-up studies repeated as appropriate to clinical disease activity, hypogonadism, and comorbid skeletal disorders (DR) (71). Bone mineral density is not a good reflection of bone quality in acromegaly, and may be normal as assessed on standard dual X-ray absorptiometry (MQ) $(78,81,88-90)$. Further studies are needed to determine the role of vitamin D supplementation and bonetargeting agents and other interventions in the prevention and treatment of vertebral fractures in acromegaly (DR). 


\section{Cancer}

The raw incidence of cancer, specifically colon and thyroid, appears to be increased in patients with acromegaly (MQ) (91). However, intensity of screening can influence reported incidence rates and confound efforts to reduce cancer incidence through routine screening (LQ) (92). Excess GH and IGF-I have been linked to colon epithelial transformation and polyposis, respectively (LQ) $(93,94)$. These observations would suggest that acromegaly patients undergo screening colonoscopy at diagnosis (DR), although there are no conclusive data linking screening frequency to colon cancer mortality rates (LQ) (95), and cancer-specific mortality rates in acromegaly are generally similar to those observed in the general population (MQ) (16). In addition, increased life expectancy of acromegaly patients has been associated with more deaths due to malignancies that are not normally related to GH/IGF-I excess. Thus, cancer incidence in acromegaly seems to be more related to age than to GH excess as observed in the general population (96).

Current evidence does not support routine screening for thyroid cancer at acromegaly diagnosis (DR) (97,98). However, thyroid ultrasound and careful evaluation is recommended in those with palpable thyroid nodules and other risk factors for thyroid cancer, consistent with guideline recommendations for the general population (SR) (99).

Follow-up and screening for all other cancers should be performed according to national/regional guidelines for the general population (SR).

\section{Impact of Comorbidities on Therapeutic Approaches}

GH levels directly reflect somatotroph tumor secretory activity and IGF-I levels reflect peripheral disease activity (HQ). Thus, despite limitations due to assay variability, GH and age- 
related IGF-I levels remain cornerstone biochemical targets for acromegaly management (SR) (2).

However, acromegaly has an adverse effect on QoL, largely due to musculoskeletal complications and persistent comorbidities (MQ) $(100,101)$, and the economic burden of disease may further adversely affect QoL (LQ) (102). Although effective treatment of acromegaly may improve QoL, biochemical control does not necessarily correlate with clinical well-being and QoL impairments often persist despite biochemical control (MQ) (101,103). A patient-centered approach, accounting for biochemical parameters, comorbidities, treatment complications, and QoL measures, should all be considered in treatment decisions (SR) (102). Scoring systems such as SAGIT (104) and ACRODAT (105) are useful to assess overall disease activity and general and acromegaly-specific QoL instruments such as AcroQoL (106) can be helpful in identifying specific factors for follow-up (DR). When GH and IGF-I levels are discrepant, and when patients are only partially responsive to treatment, clinical factors, including disease-related symptoms, should be used to assess disease control and guide treatment decisions (SR) (9).

\section{Conclusions}

Recent advances in acromegaly disease control as well as improved management of comorbidities have led to lower mortality rates, approaching those of the general population. Integrated acromegaly management requires a personalized approach to treatment (SR) (107). Effective management of comorbidities should lead to further decreased morbidity and mortality and improved QoL (SR). Pituitary Tumor Centers of Excellence (13) provide multimodal management of both biochemical dysfunction and mass effects, as well as access to a wide range of specialists to diagnose, monitor, and treat disease-related comorbidities. Such a multimodal 
approach appears effective in treating adverse comorbidities and is critical, as many patients with acromegaly will not achieve biochemical control and comorbidities may not remit even when full biochemical control is achieved (SR).

\section{Acknowledgements}

The 12th Acromegaly Consensus Conference was supported by unrestricted educational grants from Chiasma, Inc., Crinetics Pharmaceuticals, Dauntless Pharmaceuticals Inc., Ionis Pharmaceuticals, Novartis Pharmaceuticals, and Pfizer Inc. Scientific sponsorship of the meeting was provided by Cedars-Sinai Medical Center, Los Angeles, CA.

\section{Author contributions}

AG and SM served as Program Coordinators of the 12th Acromegaly Consensus Conference. NB, MDB, FEC, DC, MF, CS, PM, JW, and AVDL served as Steering Committee Members. All authors researched data for the Conference. AG and SM wrote the manuscript and all authors reviewed and/or edited the manuscript before submission. 


\section{References}

1. Melmed S. Medical progress: acromegaly. N Engl J Med. 2006; 355:2558-2573.

2. Colao A, Grasso LFS, Giustina A, Melmed S, Chanson P, Pereira AM, Pivonello R. Acromegaly. Nat Rev Dis Primers. 2019; 5:20.

3. Wassenaar MJ, Biermasz NR, van Duinen N, van der Klaauw AA, Pereira AM, Roelfsema F, Smit JW, Kroon HM, Kloppenburg M, Romijn JA. High prevalence of arthropathy, according to the definitions of radiological and clinical osteoarthritis, in patients with long-term cure of acromegaly: a case-control study. Eur J Endocrinol. 2009; 160:357-365.

4. Trotman-Dickenson B, Weetman AP, Hughes JM. Upper airflow obstruction and pulmonary function in acromegaly: relationship to disease activity. $Q \mathrm{~J}$ Med. 1991; 79:527-538.

5. Fieffe S, Morange I, Petrossians P, Chanson P, Rohmer V, Cortet C, Borson-Chazot F, Brue T, Delemer B, French Acromegaly Registry. Diabetes in acromegaly, prevalence, risk factors, and evolution: data from the French Acromegaly Registry. Eur J Endocrinol. 2011; 164:877-884.

6. Baldelli R, De Marinis L, Bianchi A, Pivonello R, Gasco V, Auriemma R, Pasimeni G, Cimino V, Appetecchia M, Maccario M, Lombardi G, Pontecorvi A, Colao A, Grottoli S. Microalbuminuria in insulin sensitivity in patients with growth hormone-secreting pituitary tumor. J Clin Endocrinol Metab. 2008; 93:710-714.

7. Berg C, Petersenn S, Lahner H, Herrmann BL, Buchfelder M, Droste M, Stalla GK, Strasburger CJ, Roggenbuck U, Lehmann N, Moebus S, Jockel KH, Mohlenkamp S, Erbel R, Saller B, Mann K, Investigative Group of the Heinz Nixdorf Recall S, the German Pegvisomant Observational Study B, Investigators. Cardiovascular risk factors in patients with uncontrolled and long-term acromegaly: comparison with matched data from the general population and the effect 
of disease control. J Clin Endocrinol Metab. 2010; 95:3648-3656.

8. Sherlock M, Ayuk J, Tomlinson JW, Toogood AA, Aragon-Alonso A, Sheppard MC, Bates AS, Stewart PM. Mortality in patients with pituitary disease. Endocr Rev. 2010;

9. Melmed S, Bronstein MD, Chanson P, Klibanski A, Casanueva FF, Wass JAH, Strasburger CJ, Luger A, Clemmons DR, Giustina A. A consensus statement on acromegaly therapeutic outcomes. Nat Rev Endocrinol. 2018; 14:552-561.

10. Katznelson L, Laws ER, Jr., Melmed S, Molitch ME, Murad MH, Utz A, Wass JA, Endocrine S. Acromegaly: an Endocrine Society clinical practice guideline. J Clin Endocrinol Metab. 2014; 99:3933-3951.

11. Giustina A, Casanueva FF, Cavagnini F, Chanson P, Clemmons D, Frohman LA, Gaillard R, Ho K, Jaquet P, Kleinberg DL, Lamberts SW, Lombardi G, Sheppard M, Strasburger CJ, Vance ML, Wass JA, Melmed S. Diagnosis and treatment of acromegaly complications. J Endocrinol Invest. 2003; 26:1242-1247.

12. Melmed S, Casanueva FF, Klibanski A, Bronstein MD, Chanson P, Lamberts SW, Strasburger CJ, Wass JA, Giustina A. A consensus on the diagnosis and treatment of acromegaly complications. Pituitary. 2013; 16:294-302.

13. Casanueva FF, Barkan AL, Buchfelder M, Klibanski A, Laws ER, Loeffler JS, Melmed S, Mortini P, Wass J, Giustina A, Pituitary Society; Expert Group on Pituitary Tumors. Criteria for the definition of Pituitary Tumor Centers of Excellence (PTCOE): a Pituitary Society statement. Pituitary. 2017; 20:489-498.

14. Guyatt GH, Oxman AD, Vist GE, Kunz R, Falck-Ytter Y, Alonso-Coello P, Schunemann HJ, Group GW. GRADE: an emerging consensus on rating quality of evidence and strength of recommendations. BMJ. 2008; 336:924-926. 
15. Swiglo BA, Murad MH, Schunemann HJ, Kunz R, Vigersky RA, Guyatt GH, Montori VM. A case for clarity, consistency, and helpfulness: state-of-the-art clinical practice guidelines in endocrinology using the grading of recommendations, assessment, development, and evaluation system. J Clin Endocrinol Metab. 2008; 93:666-673.

16. Ritvonen E, Loyttyniemi E, Jaatinen P, Ebeling T, Moilanen L, Nuutila P, KauppinenMakelin R, Schalin-Jantti C. Mortality in acromegaly: a 20-year follow-up study. Endocr Relat Cancer. 2015; 23:469-480.

17. Maione L, Brue T, Beckers A, Delemer B, Petrossians P, Borson-Chazot F, Chabre O, Francois P, Bertherat J, Cortet-Rudelli C, Chanson P, French Acromegaly Registry G. Changes in the management and comorbidities of acromegaly over three decades: the French Acromegaly Registry. Eur J Endocrinol. 2017; 176:645-655.

18. Mercado M, Gonzalez B, Vargas G, Ramirez C, de los Monteros AL, Sosa E, Jervis P, Roldan P, Mendoza V, Lopez-Felix B, Guinto G. Successful mortality reduction and control of comorbidities in patients with acromegaly followed at a highly specialized multidisciplinary clinic. J Clin Endocrinol Metab. 2014; 99:4438-4446.

19. Gadelha MR, Kasuki L, Lim DST, Fleseriu M. Systemic complications of acromegaly and the impact of the current treatment landscape: an update. Endocr Rev. 2019; 40:268-332.

20. Bondanelli M, Ambrosio MR, degli Uberti EC. Pathogenesis and prevalence of hypertension in acromegaly. Pituitary. 2001; 4:239-249.

21. Sardella C, Cappellani D, Urbani C, Manetti L, Marconcini G, Tomisti L, Lupi I, Rossi G, Scattina I, Lombardi M, Di Bello V, Marcocci C, Martino E, Bogazzi F. Disease activity and lifestyle influence comorbidities and cardiovascular events in patients with acromegaly. Eur $J$ Endocrinol. 2016; 175:443-453. 
22. Kamenicky P, Viengchareun S, Blanchard A, Meduri G, Zizzari P, Imbert-Teboul M, Doucet A, Chanson P, Lombes M. Epithelial sodium channel is a key mediator of growth hormoneinduced sodium retention in acromegaly. Endocrinology. 2008; 149:3294-3305.

23. Gonzalez B, Vargas G, de Los Monteros ALE, Mendoza V, Mercado M. Persistence of diabetes and hypertension after multimodal treatment of acromegaly. J Clin Endocrinol Metab. 2018; 103:2369-2375.

24. Warszawski L, Kasuki L, Sa R, Dos Santos Silva CM, Volschan I, Gottlieb I, Pedrosa RC, Gadelha MR. Low frequency of cardiac arrhythmias and lack of structural heart disease in medically-naive acromegaly patients: a prospective study at baseline and after 1 year of somatostatin analogs treatment. Pituitary. 2016; 19:582-589.

25. Auriemma RS, Pivonello R, De Martino MC, Cudemo G, Grasso LF, Galdiero M, Perone Y, Colao A. Treatment with GH receptor antagonist in acromegaly: effect on cardiac arrhythmias. Eur J Endocrinol. 2013; 168:15-22.

26. Unubol M, Eryilmaz U, Guney E, Ture M, Akgullu C. QT dispersion in patients with acromegaly. Endocrine. 2013; 43:419-423.

27. Breitschaft A, Hu K, Darstein C, Ligueros-Saylan M, Jordaan P, Song D, Hudson M, Shah R. Effects of subcutaneous pasireotide on cardiac repolarization in healthy volunteers: a singlecenter, phase I, randomized, four-way crossover study. J Clin Pharmacol. 2014; 54:75-86.

28. Signifor ${ }^{\circledR}$ LAR (pasireotide) [package insert]. East Hanover, NJ: Novartis Pharmaceuticals Corporation; 2019.

29. Fatti LM, Scacchi M, Lavezzi E, Pecori Giraldi F, De Martin M, Toja P, Michailidis G, Stramba-Badiale M, Cavagnini F. Effects of treatment with somatostatin analogues on QT interval duration in acromegalic patients. Clin Endocrinol (Oxf). 2006; 65:626-630. 
30. Sharma AN, Tan M, Amsterdam EA, Singh GD. Acromegalic cardiomyopathy: epidemiology, diagnosis, and management. Clin Cardiol. 2018; 41:419-425.

31. dos Santos Silva CM, Gottlieb I, Volschan I, Kasuki L, Warszawski L, Balarini Lima GA, Xavier SS, Pedrosa RC, Neto LV, Gadelha MR. Low frequency of cardiomyopathy using cardiac magnetic resonance imaging in an acromegaly contemporary cohort. J Clin Endocrinol Metab. $2015 ; 100: 4447-4455$.

32. Lombardi G, Galdiero M, Auriemma RS, Pivonello R, Colao A. Acromegaly and the cardiovascular system. Neuroendocrinology. 2006; 83:211-217.

33. Akutsu H, Kreutzer J, Wasmeier G, Ropers D, Rost C, Mohlig M, Wallaschofski H, Buchfelder M, Schofl C. Acromegaly per se does not increase the risk for coronary artery disease. Eur J Endocrinol. 2010; 162:879-886.

34. Bogazzi F, Battolla L, Spinelli C, Rossi G, Gavioli S, Di Bello V, Cosci C, Sardella C, Volterrani D, Talini E, Pepe P, Falaschi F, Mariani G, Martino E. Risk factors for development of coronary heart disease in patients with acromegaly: a five-year prospective study. $J$ Clin Endocrinol Metab. 2007; 92:4271-4277.

35. Maison P, Tropeano AI, Macquin-Mavier I, Giustina A, Chanson P. Impact of somatostatin analogs on the heart in acromegaly: a metaanalysis. J Clin Endocrinol Metab. 2007; 92:1743-1747. 36. Pivonello R, Galderisi M, Auriemma RS, De Martino MC, Galdiero M, Ciccarelli A, D'Errico A, Kourides I, Burman P, Lombardi G, Colao A. Treatment with growth hormone receptor antagonist in acromegaly: effect on cardiac structure and performance. J Clin Endocrinol Metab. 2007; 92:476-482.

37. Colao A, Marek J, Goth MI, Caron P, Kuhn JM, Minuto FM, Weissman NJ. No greater incidence or worsening of cardiac valve regurgitation with somatostatin analog treatment of 
acromegaly. J Clin Endocrinol Metab. 2008; 93:2243-2248.

38. Maione L, Garcia C, Bouchachi A, Kallel N, Maison P, Salenave S, Young J, Assayag P, Chanson P. No evidence of a detrimental effect of cabergoline therapy on cardiac valves in patients with acromegaly. J Clin Endocrinol Metab. 2012; 97:E1714-1719.

39. Alexopoulou O, Bex M, Kamenicky P, Mvoula AB, Chanson P, Maiter D. Prevalence and risk factors of impaired glucose tolerance and diabetes mellitus at diagnosis of acromegaly: a study in 148 patients. Pituitary. 2014; 17:81-89.

40. Petrossians P, Daly AF, Natchev E, Maione L, Blijdorp K, Sahnoun-Fathallah M, Auriemma R, Diallo AM, Hulting AL, Ferone D, Hana V, Jr., Filipponi S, Sievers C, Nogueira C, Fajardo-Montanana C, Carvalho D, Hana V, Stalla GK, Jaffrain-Rea ML, Delemer B, Colao A, Brue T, Neggers S, Zacharieva S, Chanson P, Beckers A. Acromegaly at diagnosis in 3173 patients from the Liege Acromegaly Survey (LAS) Database. Endocr Relat Cancer. 2017; 24:505-518.

41. Hannon AM, Thompson CJ, Sherlock M. Diabetes in patients with acromegaly. Curr Diab Rep. 2017; 17:8.

42. Quarella M, Walser D, Brandle M, Fournier JY, Bilz S. Rapid onset of diabetic ketoacidosis after SGLT2 inhibition in a patient with unrecognized acromegaly. J Clin Endocrinol Metab. 2017; 102:1451-1453.

43. Mazziotti G, Floriani I, Bonadonna S, Torri V, Chanson P, Giustina A. Effects of somatostatin analogs on glucose homeostasis: a metaanalysis of acromegaly studies. $J$ Clin Endocrinol Metab. 2009; 94:1500-1508.

44. Colao A, Bronstein M, Freda P, Gu F, Shen CC, Gadelha M, Fleseriu M, van der Lely A, Farrall A, Hermosillo Resendiz K, Ruffin M, Chen Y, Sheppard M, on behalf of the Pasireotide CSG. Pasireotide versus octreotide in acromegaly: a head-to-head superiority study. J Clin 
Endocrinol Metab. 2014; 99:791-799.

45. Schmid HA, Brue T, Colao A, Gadelha MR, Shimon I, Kapur K, Pedroncelli AM, Fleseriu M. Effect of pasireotide on glucose- and growth hormone-related biomarkers in patients with inadequately controlled acromegaly. Endocrine. 2016; 53:210-219.

46. Breitschaft A, Hu K, Hermosillo Resendiz K, Darstein C, Golor G. Management of hyperglycemia associated with pasireotide (SOM230): healthy volunteer study. Diabetes Res Clin Pract. 2014; 103:458-465.

47. Barkan AL, Burman P, Clemmons DR, Drake WM, Gagel RF, Harris PE, Trainer PJ, van der Lely AJ, Vance ML. Glucose homeostasis and safety in patients with acromegaly converted from long-acting octreotide to pegvisomant. J Clin Endocrinol Metab. 2005; 90:5684-5691.

48. Feola T, Cozzolino A, Simonelli I, Sbardella E, Pozza C, Giannetta E, Gianfrilli D, Pasqualetti P, Lenzi A, Isidori AM. Pegvisomant improves glucose metabolism in acromegaly: a meta-analysis of prospective interventional studies. J Clin Endocrinol Metab. 2019; 104:28922902.

49. Pivonello R, Auriemma RS, Grasso LF, Pivonello C, Simeoli C, Patalano R, Galdiero M, Colao A. Complications of acromegaly: cardiovascular, respiratory and metabolic comorbidities. Pituitary. 2017; 20:46-62.

50. Grynberg M, Salenave S, Young J, Chanson P. Female gonadal function before and after treatment of acromegaly. J Clin Endocrinol Metab. 2010; 95:4518-4525.

51. Drange MR, Fram NR, Herman-Bonert V, Melmed S. Pituitary tumor registry: a novel clinical resource. J Clin Endocrinol Metab. 2000; 85:168-174.

52. Bredella MA, Schorr M, Dichtel LE, Gerweck AV, Young BJ, Woodmansee WW, Swearingen B, Miller KK. Body composition and ectopic lipid changes with biochemical control 
of acromegaly. J Clin Endocrinol Metab. 2017; 102:4218-4225.

53. Jorgensen JO, Christensen JJ, Vestergaard E, Fisker S, Ovesen P, Christiansen JS. Sex steroids and the growth hormone/insulin-like growth factor-I axis in adults. Horm Res. 2005; 64 Suppl 2:37-40.

54. Duarte FH, Jallad RS, Bronstein MD. Clomiphene citrate for treatment of acromegaly not controlled by conventional therapies. J Clin Endocrinol Metab. 2015; 100:1863-1869.

55. Klose M, Marina D, Hartoft-Nielsen ML, Klefter O, Gavan V, Hilsted L, Rasmussen AK, Feldt-Rasmussen U. Central hypothyroidism and its replacement have a significant influence on cardiovascular risk factors in adult hypopituitary patients. J Clin Endocrinol Metab. 2013; 98:3802-3810.

56. Mazziotti G, Formenti AM, Frara S, Roca E, Mortini P, Berruti A, Giustina A. Management of endocrine disease: risk of overtreatment in patients with adrenal insufficiency: current and emerging aspects. Eur J Endocrinol. 2017; 177:R231-R248.

57. Sherlock M, Reulen RC, Alonso AA, Ayuk J, Clayton RN, Sheppard MC, Hawkins MM, Bates AS, Stewart PM. ACTH deficiency, higher doses of hydrocortisone replacement, and radiotherapy are independent predictors of mortality in patients with acromegaly. J Clin Endocrinol Metab. 2009; 94:4216-4223.

58. Agha A, Monson JP. Modulation of glucocorticoid metabolism by the growth hormone IGF-1 axis. Clin Endocrinol (Oxf). 2007; 66:459-465.

59. Fleseriu M, Hashim IA, Karavitaki N, Melmed S, Murad MH, Salvatori R, Samuels MH. Hormonal replacement in hypopituitarism in adults: an Endocrine Society Clinical Practice Guideline. J Clin Endocrinol Metab. 2016; 101:3888-3921.

60. Annamalai AK, Webb A, Kandasamy N, Elkhawad M, Moir S, Khan F, Maki-Petaja K, 
Gayton EL, Strey CH, O'Toole S, Ariyaratnam S, Halsall DJ, Chaudhry AN, Berman L, Scoffings DJ, Antoun NM, Dutka DP, Wilkinson IB, Shneerson JM, Pickard JD, Simpson HL, Gurnell M. A comprehensive study of clinical, biochemical, radiological, vascular, cardiac, and sleep parameters in an unselected cohort of patients with acromegaly undergoing presurgical somatostatin receptor ligand therapy. J Clin Endocrinol Metab. 2013; 98:1040-1050.

61. Zhang Z, Li Q, He W, Qiu H, Ye H, Wang Y, Shen M, He M, Yu Y, Shou X, Huang C, Yu H, Huang G, Tang W, Geng D, Fu C, Liu C, Ma Z, Ye Z, Zhang Q, Zhang Y, Shen Y, Yang Y, Wang M, Liu X, Lu Y, Hu R, Mao Y, Zhou L, Li Y, Li S, Tritos NA, Zhao Y. The comprehensive impact on human body induced by resolution of growth hormone excess. Eur $J$ Endocrinol. 2018; 178:365-375.

62. Kuhn E, Maione L, Bouchachi A, Roziere M, Salenave S, Brailly-Tabard S, Young J, Kamenicky P, Assayag P, Chanson P. Long-term effects of pegvisomant on comorbidities in patients with acromegaly: a retrospective single-center study. Eur J Endocrinol. 2015; 173:693702.

63. Guo X, Gao L, Zhao Y, Wang M, Jiang B, Wang Q, Wang Z, Liu X, Feng M, Wang R, Zhang Z, Xing B. Characteristics of the upper respiratory tract in patients with acromegaly and correlations with obstructive sleep apnoea/hypopnea syndrome. Sleep Med. 2018; 48:27-34.

64. Dostalova S, Sonka K, Smahel Z, Weiss V, Marek J, Horinek D. Craniofacial abnormalities and their relevance for sleep apnoea syndrome aetiopathogenesis in acromegaly. Eur J Endocrinol. $2001 ; 144: 491-497$.

65. Attal P, Chanson P. Endocrine aspects of obstructive sleep apnea. J Clin Endocrinol Metab. 2010; 95:483-495.

66. Chemla D, Attal P, Maione L, Veyer AS, Mroue G, Baud D, Salenave S, Kamenicky P, 
Bobin S, Chanson P. Impact of successful treatment of acromegaly on overnight heart rate variability and sleep apnea. J Clin Endocrinol Metab. 2014; 99:2925-2931.

67. Davi MV, Dalle Carbonare L, Giustina A, Ferrari M, Frigo A, Lo Cascio V, Francia G. Sleep apnoea syndrome is highly prevalent in acromegaly and only partially reversible after biochemical control of the disease. Eur J Endocrinol. 2008; 159:533-540.

68. Olarescu NC, Heck A, Godang K, Ueland T, Bollerslev J. The metabolic risk in patients newly diagnosed with acromegaly is related to fat distribution and circulating adipokines and improves after treatment. Neuroendocrinology. 2016; 103:197-206.

69. Colao A, Pivonello R, Grasso LF, Auriemma RS, Galdiero M, Savastano S, Lombardi G. Determinants of cardiac disease in newly diagnosed patients with acromegaly: results of a 10 year survey study. Eur J Endocrinol. 2011; 165:713-721.

70. Dal J, Feldt-Rasmussen U, Andersen M, Kristensen LO, Laurberg P, Pedersen L, Dekkers OM, Sorensen HT, Jorgensen JO. Acromegaly incidence, prevalence, complications and long-term prognosis: a nationwide cohort study. Eur J Endocrinol. 2016; 175:181-190.

71. Claessen KM, Mazziotti G, Biermasz NR, Giustina A. Bone and joint disorders in acromegaly. Neuroendocrinology. 2016; 103:86-95.

72. Claessen KM, Ramautar SR, Pereira AM, Smit JW, Roelfsema F, Romijn JA, Kroon HM, Kloppenburg M, Biermasz NR. Progression of acromegalic arthropathy despite long-term biochemical control: a prospective, radiological study. Eur J Endocrinol. 2012; 167:235-244.

73. Claessen KM, Ramautar SR, Pereira AM, Romijn JA, Kroon HM, Kloppenburg M, Biermasz NR. Increased clinical symptoms of acromegalic arthropathy in patients with long-term disease control: a prospective follow-up study. Pituitary. 2014; 17:44-52.

74. Claessen K, Canete AN, de Bruin PW, Pereira AM, Kloppenburg M, Kroon HM, Biermasz 
NR. Acromegalic arthropathy in various stages of the disease: an MRI study. Eur J Endocrinol. 2017; 176:779-790.

75. Tagliafico A, Resmini E, Nizzo R, Bianchi F, Minuto F, Ferone D, Martinoli C. Ultrasound measurement of median and ulnar nerve cross-sectional area in acromegaly. J Clin Endocrinol Metab. 2008; 93:905-909.

76. Sasagawa $\mathrm{Y}$, Tachibana $\mathrm{O}$, Doai M, Tonami H, Iizuka H. Median nerve conduction studies and wrist magnetic resonance imaging in acromegalic patients with carpal tunnel syndrome. Pituitary. 2015; 18:695-700.

77. Resmini E, Tagliafico A, Nizzo R, Bianchi F, Minuto F, Derchi L, Martinoli C, Ferone D. Ultrasound of peripheral nerves in acromegaly: changes at 1-year follow-up. Clin Endocrinol (Oxf). 2009; 71:220-225.

78. Claessen KM, Kroon HM, Pereira AM, Appelman-Dijkstra NM, Verstegen MJ, Kloppenburg M, Hamdy NA, Biermasz NR. Progression of vertebral fractures despite long-term biochemical control of acromegaly: a prospective follow-up study. J Clin Endocrinol Metab. 2013; 98:4808-4815.

79. Bonadonna S, Mazziotti G, Nuzzo M, Bianchi A, Fusco A, De Marinis L, Giustina A. Increased prevalence of radiological spinal deformities in active acromegaly: a cross-sectional study in postmenopausal women. J Bone Miner Res. 2005; 20:1837-1844.

80. Mazziotti G, Frara S, Giustina A. Pituitary diseases and bone. Endocr Rev. 2018; 39:440488.

81. Mazziotti G, Biagioli E, Maffezzoni F, Spinello M, Serra V, Maroldi R, Floriani I, Giustina A. Bone turnover, bone mineral density, and fracture risk in acromegaly: a meta-analysis. J Clin Endocrinol Metab. 2015; 100:384-394. 
82. Dalle Carbonare L, Micheletti V, Cosaro E, Valenti MT, Mottes M, Francia G, Davi MV. Bone histomorphometry in acromegaly patients with fragility vertebral fractures. Pituitary. 2018; 21:56-64.

83. Silva PPB, Amlashi FG, Yu EW, Pulaski-Liebert KJ, Gerweck AV, Fazeli PK, Lawson E, Nachtigall LB, Biller BMK, Miller KK, Klibanski A, Bouxsein M, Tritos NA. Bone microarchitecture and estimated bone strength in men with active acromegaly. Eur J Endocrinol. 2017; 177:409-420.

84. Chiloiro S, Mormando M, Bianchi A, Giampietro A, Milardi D, Bima C, Grande G, Formenti AM, Mazziotti G, Pontecorvi A, Giustina A, De Marinis L. Prevalence of morphometric vertebral fractures in "difficult" patients with acromegaly with different biochemical outcomes after multimodal treatment. Endocrine. 2018; 59:449-453.

85. Chiloiro S, Mazziotti G, Giampietro A, Bianchi A, Frara S, Mormando M, Pontecorvi A, Giustina A, De Marinis L. Effects of pegvisomant and somatostatin receptor ligands on incidence of vertebral fractures in patients with acromegaly. Pituitary. 2018; 21:302-308.

86. Parkinson C, Kassem M, Heickendorff L, Flyvbjerg A, Trainer PJ. Pegvisomant-induced serum insulin-like growth factor-I normalization in patients with acromegaly returns elevated markers of bone turnover to normal. J Clin Endocrinol Metab. 2003; 88:5650-5655.

87. Mazziotti G, Bianchi A, Porcelli T, Mormando M, Maffezzoni F, Cristiano A, Giampietro A, De Marinis L, Giustina A. Vertebral fractures in patients with acromegaly: a 3-year prospective study. J Clin Endocrinol Metab. 2013; 98:3402-3410.

88. Maffezzoni F, Maddalo M, Frara S, Mezzone M, Zorza I, Baruffaldi F, Doglietto F, Mazziotti G, Maroldi R, Giustina A. High-resolution-cone beam tomography analysis of bone microarchitecture in patients with acromegaly and radiological vertebral fractures. Endocrine. 
2016; 54:532-542.

89. Kuzma M, Vanuga P, Sagova I, Pavai D, Jackuliak P, Killinger Z, Binkley NC, Winzenrieth R, Genant HK, Payer J. Non-invasive DXA-derived bone structure assessment of acromegaly patients: a cross-sectional study. Eur J Endocrinol. 2019; 180:201-211.

90. Malgo F, Hamdy NAT, Rabelink TJ, Kroon HM, Claessen K, Pereira AM, Biermasz NR, Appelman-Dijkstra NM. Bone material strength index as measured by impact microindentation is altered in patients with acromegaly. Eur J Endocrinol. 2017; 176:339-347.

91. Dal J, Leisner MZ, Hermansen K, Farkas DK, Bengtsen M, Kistorp C, Nielsen EH, Andersen M, Feldt-Rasmussen U, Dekkers OM, Sorensen HT, Jorgensen JOL. Cancer incidence in patients with acromegaly: a cohort study and meta-analysis of the literature. J Clin Endocrinol Metab. 2018; 103:2182-2188.

92. Boguszewski CL, Boguszewski M. Growth hormone's links to cancer. Endocr Rev. 2019; 40:558-574.

93. Chesnokova V, Zonis S, Barrett R, Kameda H, Wawrowsky K, Ben-Shlomo A, Yamamoto M, Gleeson J, Bresee C, Gorbunova V, Melmed S. Excess growth hormone suppresses DNA damage repair in epithelial cells. JCI Insight. 2019; 4:e125762.

94. Chesnokova V, Zonis S, Zhou C, Recouvreux MV, Ben-Shlomo A, Araki T, Barrett R, Workman M, Wawrowsky K, Ljubimov VA, Uhart M, Melmed S. Growth hormone is permissive for neoplastic colon growth. Proc Natl Acad Sci U S A. 2016; 113:E3250-3259.

95. Lois K, Bukowczan J, Perros P, Jones S, Gunn M, James RA. The role of colonoscopic screening in acromegaly revisited: review of current literature and practice guidelines. Pituitary. 2015; 18:568-574.

96. Bolfi F, Neves AF, Boguszewski CL, Nunes-Nogueira VS. Mortality in acromegaly 
decreased in the last decade: a systematic review and meta-analysis. Eur J Endocrinol. 2018; 179:59-71.

97. Wolinski K, Czarnywojtek A, Ruchala M. Risk of thyroid nodular disease and thyroid cancer in patients with acromegaly--meta-analysis and systematic review. PLoS One. 2014; 9:e88787.

98. Reverter JL, Fajardo C, Resmini E, Salinas I, Mora M, Llatjos M, Sesmilo G, Rius F, Halperin I, Webb SM, Ricart V, Riesgo P, Mauricio D, Puig-Domingo M. Benign and malignant nodular thyroid disease in acromegaly. Is a routine thyroid ultrasound evaluation advisable? PLoS One. 2014; 9:e104174.

99. Haugen BR, Alexander EK, Bible KC, Doherty GM, Mandel SJ, Nikiforov YE, Pacini F, Randolph GW, Sawka AM, Schlumberger M, Schuff KG, Sherman SI, Sosa JA, Steward DL, Tuttle RM, Wartofsky L. 2015 American Thyroid Association management guidelines for adult patients with thyroid nodules and differentiated thyroid cancer: the American Thyroid Association GUIDELINES TASK FORCE ON THYROID NODULES AND DIFFERENTIATed thyroid cancer. Thyroid. 2016; 26:1-133.

100. Andela CD, Scharloo M, Pereira AM, Kaptein AA, Biermasz NR. Quality of life (QoL) impairments in patients with a pituitary adenoma: a systematic review of QoL studies. Pituitary. $2015 ; 18: 752-776$.

101. Geraedts VJ, Andela CD, Stalla GK, Pereira AM, van Furth WR, Sievers C, Biermasz NR. Predictors of quality of life in acromegaly: no consensus on biochemical parameters. Front Endocrinol (Lausanne). 2017; 8:40.

102. Ben-Shlomo A, Sheppard MC, Stephens JM, Pulgar S, Melmed S. Clinical, quality of life, and economic value of acromegaly disease control. Pituitary. 2011; 14:284-294. 
103. Kyriakakis N, Lynch J, Gilbey SG, Webb SM, Murray RD. Impaired quality of life in patients with treated acromegaly despite long-term biochemically stable disease: Results from a 5years prospective study. Clin Endocrinol (Oxf). 2017; 86:806-815.

104. Giustina A, Bevan JS, Bronstein MD, Casanueva FF, Chanson P, Petersenn S, Thanh XM, Sert C, Houchard A, Guillemin I, Melmed S, Group SI. SAGIT(R): clinician-reported outcome instrument for managing acromegaly in clinical practice--development and results from a pilot study. Pituitary. 2016; 19:39-49.

105. van der Lely AJ, Gomez R, Pleil A, Badia X, Brue T, Buchfelder M, Burman P, Clemmons D, Ghigo E, Jorgensen JOL, Luger A, van der Lans-Bussemaker J, Webb SM, Strasburger CJ. Development of ACRODAT(R), a new software medical device to assess disease activity in patients with acromegaly. Pituitary. 2017; 20:692-701.

106. Webb SM, Badia X, Surinach NL, Spanish AcroQol Study G. Validity and clinical applicability of the acromegaly quality of life questionnaire, AcroQoL: a 6-month prospective study. Eur J Endocrinol. 2006; 155:269-277.

107. Melmed S. Pituitary medicine from discovery to patient-focused outcomes. J Clin Endocrinol Metab. 2016; 101:769-777.

108. Giustina A, Chanson P, Kleinberg D, Bronstein MD, Clemmons DR, Klibanski A, van der Lely AJ, Strasburger CJ, Lamberts SW, Ho KK, Casanueva FF, Melmed S. Expert consensus document: A consensus on the medical treatment of acromegaly. Nat Rev Endocrinol. 2014; $10: 243-248$. 
Table 1. Grading of Evidence and Recommendations

\begin{tabular}{|c|c|}
\hline Grading the evidence & Grading the recommendations \\
\hline $\begin{array}{l}\text { - Very low quality (VLQ): expert opinion } \\
\text { supported by one or few small } \\
\text { uncontrolled studies } \\
\text { - Low quality (LQ): supported by large } \\
\text { series of small uncontrolled studies } \\
\text { Moderate quality (MQ): supported by one } \\
\text { or few large uncontrolled studies or meta- } \\
\text { analyses } \\
\text { High quality (HQ): supported by } \\
\text { controlled studies or large series of large } \\
\text { uncontrolled studies with sufficiently long } \\
\text { follow-up }\end{array}$ & $\begin{array}{l}\text { Discretionary recommendation (DR): } \\
\text { based on VLQ or LQ evidence } \\
\text { - Strong recommendation (SR): based on } \\
\text { MQ or HQ evidence }\end{array}$ \\
\hline
\end{tabular}

Adapted with permission from Giustina et al (108) 
Table 2. Key Consensus Recommendations for Diagnosis and Treatment of Acromegaly Complications

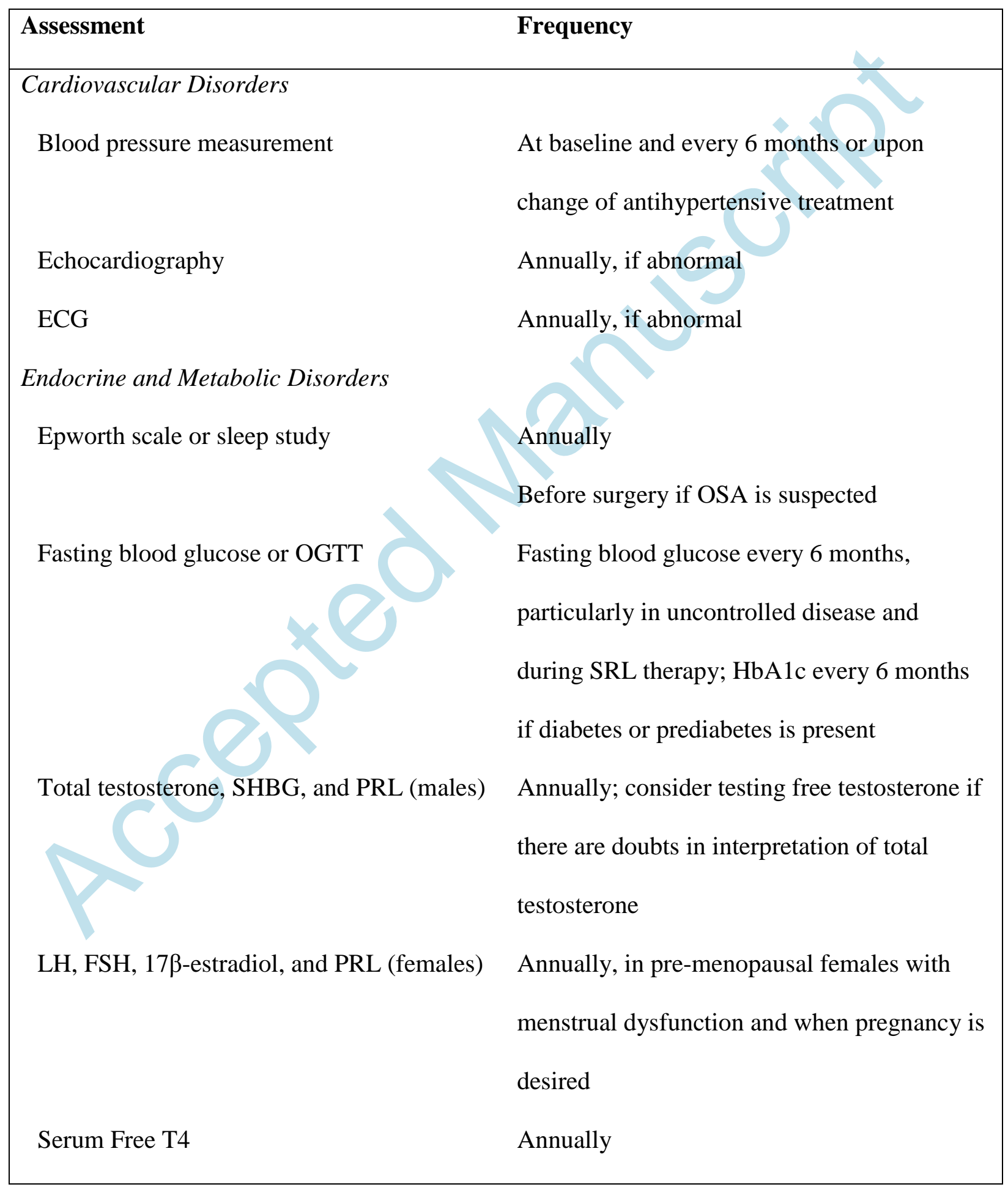




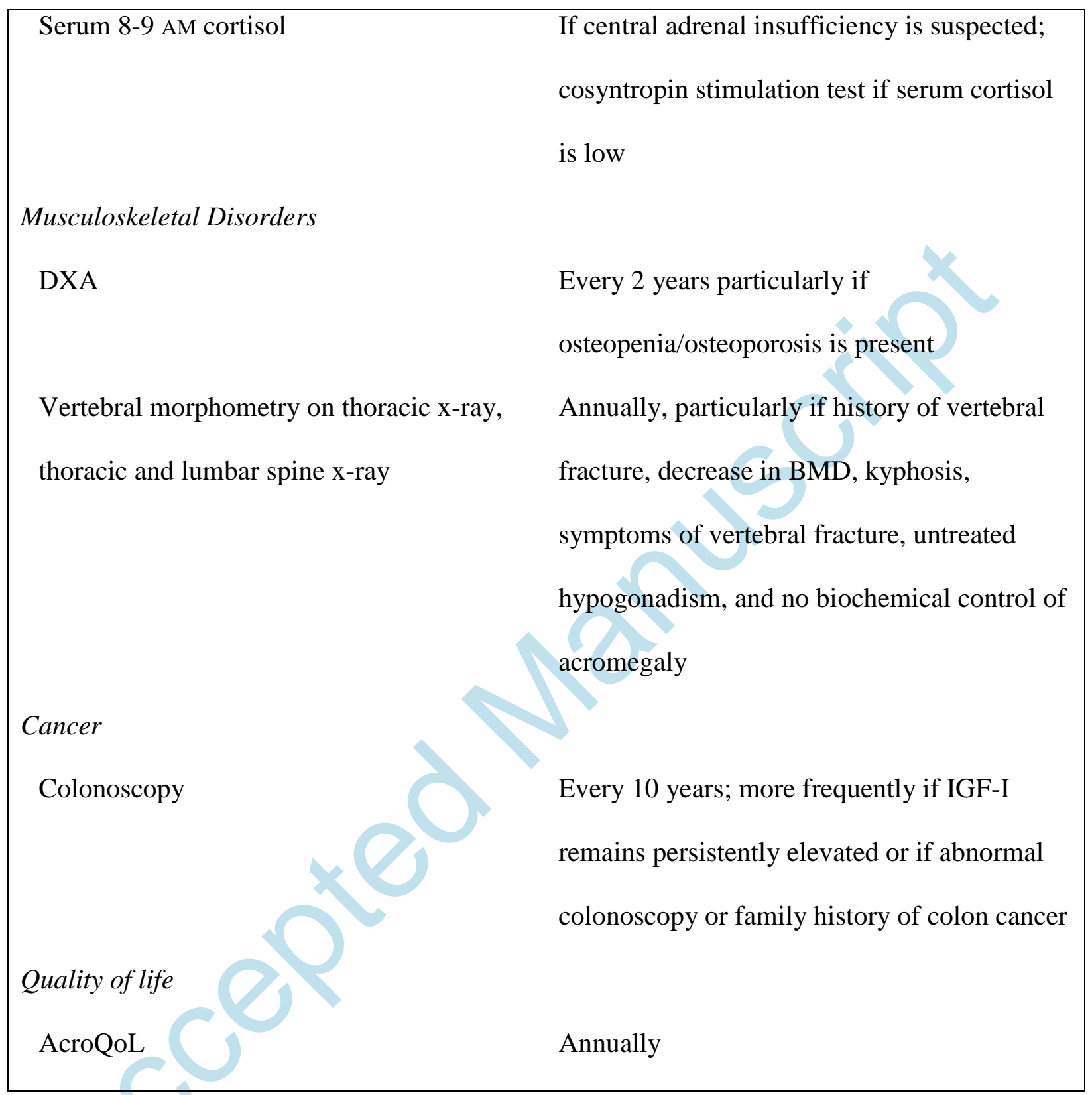

